TRADUÇÃO 

Nuntius Antiquus, Belo Horizonte, v. 11, n. 2, p. 143-152, 2015

\title{
Horácio, Odes, I.37. Apresentação e tradução
}

\section{Horace, Odes, 1.37. Presentation and translation}

\begin{abstract}
Daniel da Silva Moreira
Departamento de Letras da Universidade Federal de Juiz de Fora moreiradsm@gmail.com
\end{abstract}

Resumo: O presente texto propõe uma nova tradução versificada da ode I.37, do poeta romano Horácio (65 a.C. -8 a.C.). Precede-o uma breve contextualização do evento histórico evocado pelo poema, a batalha de Ácio (Actium) - travada em 2 de setembro de 31 a.C. no mar Jônico, próximo à cidade de Ácio, na província romana da Macedônia-, algumas notas que, baseadas em bibliografia atualizada sobre o tema, tratam sobre as estratégias discursivas escolhidas pelo poeta para representar, ou omitir, os personagens envolvidos na batalha, e, finalmente, algumas considerações, ainda que o mais sucintas possível, sobre a tradução da estrofe alcaica.

Palavras-chave: Horácio; Odes; poesia lírica; batalha de Ácio; tradução.

Abstract: This paper proposes a new versified translation of the ode 1.37 , by the Roman poet Horace $(65 \mathrm{BC}-8 \mathrm{BC})$. It is preceded by a brief contextualization of the historical event evocated by the poem, the Actium battle - fought on September 2, 31 BC in the Ionian Sea, near the city of Actium, in the Roman province of Macedonia -, a few notes, based on updated bibliography on the topic, on the discursive strategies chosen by the poet to represent, or to omit, the characters involved in the battle, and, finally, some considerations, as succinct as possible, on the translation of alcaic stanza.

Keywords: Horace; Odes; lyric poetry; Actium battle; translation. 
Recebido em 27 de junho de 2015 Aprovado em 14 de setembro de 2015

\section{Sobre a ode I.37, de Horácio}

O poema que apresento em tradução faz referência a um dos eventos mais importantes na história do Ocidente. A batalha de Ácio (Actium) - travada em 2 de setembro de 31 a.C. no mar Jônico, próximo à cidade de Ácio, na província romana da Macedônia - foi o evento decisivo da guerra civil entre Otávio César e Marco Antônio, que já durava 2 anos. A vitória das frotas de Otávio sobre as de Marco Antônio e Cleópatra vai representar a eliminação do último impedimento para que se estabelecesse o poder absoluto do futuro imperador Augusto, que viria a fundar um modo de governar que duraria pelo menos mais 400 anos e teria implicações profundas tanto para a história de Roma quanto, consequentemente, para a constituição de toda a história ocidental.

O poema 37 do primeiro livro das Odes de Horácio (65 a.C. a 8 a.C.), muitas vezes conhecido como a "ode de Cleópatra", aborda a batalha de Ácio e seus personagens de um modo bastante peculiar. Muito mais do que fornecer ao leitor um sem-fim de dados históricos que descrevessem minuciosamente os antecedentes, as motivações e o desenrolar da guerra que culminou na batalha de Ácio, creio que torne a leitura mais proveitosa e ampla manter o foco justamente no que há de mais característico no poema, nos momentos em que a versão dos fatos, tal como apresentada por Horácio, seja divergente da registrada pela história. Assim, ofereço a seguir, ainda que o mais brevemente possível, algumas notas, colhidas na bibliografia mais significativa sobre a poesia horaciana, que tratam das estratégias discursivas escolhidas pelo poeta para representar, ou omitir, as figuras envolvidas na batalha de Ácio.

Ronnie Ancona, ao tratar dessa ode, afirma que "muito de seu sucesso se baseia no retrato maravilhosamente ambíguo da rainha ptolomaica, Cleópatra VII do Egito, uma figura central para a política romana contemporânea" (ANCONA, 2010, p. 183). Cleópatra é, de

\footnotetext{
${ }^{1}$ No original: "Much of its success lies in its marvelously ambiguous portrayal of the Ptolemaic queen, Cleopatra VII of Egypt, a central figure for contemporary Roman politics" (todas as traduções apresentadas nesse texto são de minha autoria).
} 
fato, a personagem central do poema e, como a autora propõe, o perfil da rainha egípcia que ali se delineia é dúbio. Temos, de um lado, as cinco primeiras estrofes do poema em que Horácio celebra a derrota do fatale monstrum, e, de outro, as três últimas estrofes em que vemos crescer a nobreza de Cleópatra face à derrota (ANCONA, 2007, p. 58). Ancona propõe ainda que uma leitura do poema coloque em questão se a ambiguidade na representação da rainha egípcia expressaria uma ambivalência da parte de Horácio quanto à vitória de Otávio sobre sua oponente ou se, em outro sentido, o gesto de ressaltar a notável dignidade de Cleópatra seria uma estratégia para tornar a conquista de César ainda mais proeminente (ANCONA, 2007, p. 58).

Em Polyhymnia: the rhetoric of horatian lyric discourse, Gregson Davis também investiga o modo como Cleópatra passa, no decurso do poema, de detractanda a laudanda (DAVIS, 1991, p. 233), para o que propõe que esse tratamento paradoxal da rainha se dá no contexto de uma conversão que conduziria o poema para um sentido final totalmente alinhado a um programa encomiástico favorável ao futuro Augusto. Para Davis, "apesar do destaque concedido a Cleópatra na narrativa, a agenda retórica oblíqua é louvar o governante cujo nome aparece na exata metade do poema: Caesar (verso 16)" (DAVIS, 1991, p. 233). ${ }^{2}$ E, assim, a transfiguração do caráter da rainha em direção a uma imagem nobre e positiva mostraria, na verdade, o poder transformativo de Augusto, aquele que deveria ser louvado em última instância.

Michèle Lowrie, em Horace's narrative odes, chama a atenção para a habilidade narrativa do poeta ao comprimir toda a extensão da última guerra civil do período republicano em apenas três cenas: "Dois anos, 31 e 30 a.C., são condensados em três cenas (ameaça, conflito e perseguição, derrota) que se seguem suavemente uma após outra" (LOWRIE, 1997, p. 144). ${ }^{3}$ Os três momentos dessa narrativa poderiam ser divididos do seguinte modo: a cena de ameaça iria dos versos 01 a 12 , o conflito e a perseguição estariam entre os versos 12 e 24 e, por fim, a cena da derrota de Cleópatra se situaria entre os versos 25 e 32 .

\footnotetext{
${ }^{2}$ No original: "Despite the prominence accorded to Cleopatra in the narrative, the oblique rhetorical agenda is praise of the ruler whose name appears at the precise midpoint of the poem: Caesar (line 16)".

${ }^{3}$ No original: "Two years, 31 and $30 \mathrm{BC}$, condense into three scenes (threat, conflict and chase, defeat) following smoothly one on the other".
} 
A suavidade com que as cenas se sucedem, para Lowrie, adviria da estratégia e do foco narrativos escolhidos por Horácio para se valer dos acontecimentos envolvidos na batalha de Acio, uma perspectiva que, ao encadear longos períodos históricos, teria o efeito de criar sua própria versão lírica da história, em inúmeros pontos distinta da dos registros históricos:

Certos aspectos refutam os "fatos" tais como conhecidos a partir de Dion e de Plutarco (...). César não perseguiu Cleópatra ele próprio; ela de fato planejou esconder sua frota, até ser frustrada pela logística; seu palácio não se arruinou fisicamente; a historicidade das serpentes é questionável. Essas disparidades entre a "realidade" histórica e sua representação transformam a história em mito. ${ }^{4}$ (LOWRIE, 1997, p. 144)

Um dos pontos de maior interesse para a leitura da ode de Horácio está no fato de o poeta, num poema que faz referência à batalha de Ácio, não mencionar Marco Antônio diretamente em momento algum. Para Lowrie, "O apagamento de Marco Antônio em favor da deslumbrante Cleópatra transforma a batalha de Ácio, enquanto um conflito interno, em um externo; enquanto uma guerra civil, em uma guerra estrangeira" (LOWRIE, 1997, p. 145). ${ }^{5}$ A omissão desse personagem fundamental da guerra é vista, tradicionalmente, como uma estratégia narrativa participante da atitude conciliadora que a política augustana parece ter mantido desde seu início, buscando amenizar a polarização entre os partidários de Otávio e os antigos partidários de Marco Antônio, tornando Roma, assim, governável. E essa busca de conciliação, é claro, também se exprimiu através da literatura de propaganda do período augustano, da qual participam as Odes horacianas. Para Michèle Lowrie, contudo, a omissão de Marco Antônio é antes uma questão de gênero. A autora nota que, numa representação convencional da batalha de Ácio, figuraria uma batalha naval entre Marco Antônio e Otávio, dando ênfase ao último -

\footnotetext{
${ }^{4}$ No original: "Certain aspects confute the 'facts' as known from Dio and Plutarch (...). Caesar did not pursue Cleopatra himself; she did plan to hide her fleet until thwarted by logistics; her palace did not collapse physically; the snakes' historicity is tenuous. These disparities between historical 'reality' and its representation turn history into myth". ${ }^{5}$ No original: "The erasure of Antony in favour of the dazzling Cleopatra transforms the battle of Actium from internal to external conflict, from civil war to foreign war".
} 
algo como o que Virgílio coloca no escudo de Eneias, no canto VIII da Eneida-, mas, no caso da ode I.37, Marco Antônio desaparece e Otávio não é o protagonista. Qual seria então a vantagem de se dar destaque a Cleópatra em detrimento de um retrato convencional da batalha? Lowrie, baseando-se em uma leitura da ode feita por Charles Martindale, afirma que o poema tenta modificar a significação de Ácio em termos de ideologias sociais, raciais e sexuais. A omissão de outros participantes no evento histórico traz para o primeiro plano da narrativa a oposição entre mulher e homem, a rainha do Egito e o líder de Roma, e, enquanto este último se torna o uir por excelência, Cleópatra assume o lugar de uma "outra", tanto em termos étnicos quanto em termos de gênero. Assim, a transformação da batalha de Ácio em uma guerra estrangeira substitui um conflito entre iguais por outro contra uma alteridade radical: "No lugar de dois aristocratas romanos racionais, a figura de Cleópatra permite uma oposição mais clara: homem versus mulher, romano versus egípcio, racional versus irracional, civilizado versus bárbaro" (LOWRIE, 1997, p. 149). ${ }^{6}$

\section{Sobre a estrofe alcaica e sua tradução}

A ode I.37 emprega em sua composição a estrofe alcaica, cujo nome deriva do poeta grego Alceu de Mitilene (c. 630 - c. 580 a.C.), tido como o inventor dessa combinação de metros. Nas Odes, Horácio emprega a estrofe em 37 poemas ${ }^{7}$ e parece haver uma íntima relação entre o emprego desse tipo de estrofe, a temática política/patriótica e a poesia simposiástica. ${ }^{8}$ A estrofe alcaica caracteriza-se pela variedade métrica/ rítmica, sendo os dois primeiros versos hendecassílabos, o terceiro eneassílabo e o último decassílabo (CAMPOS, s.d., p. 14).

\footnotetext{
${ }^{6}$ No original: "Instead of two rational male Roman aristocrats, the figure of Cleopatra allows a more clear-cut opposition: male versus female, Roman versus Egyptian, rational versus irrational, civilized versus barbarian".

${ }^{7}$ I) $9,16,17,26,27,29,31,34,35$, 37; II) $1,3,5,7,9,11,13,14,15,17,19,20$; III) $1,2,3,4,5,6,17,21,23,26,29$; IV) 4, 9, 14, 15.

${ }^{8} \mathrm{O}$ simpósio, na antiga Grécia, era a segunda parte de um banquete ou festim, durante a qual os convidados bebiam, conversavam, ouviam música e se entregavam a outros divertimentos. A poesia lírica grega e, posteriormente, a latina emularam a prática em poemas que tratam das alegrias do vinho, da comemoração do sucesso de batalhas, da amizade, entre outros assuntos.
} 
Antes de escolher qual modelo dentro do sistema versificatório românico adotar para a tradução da ode I.37, imaginei que seria importante verificar como a estrofe vinha sendo traduzida para o verso português. Em sua tradução das Odes e epodos de Horácio, ainda que não inclua a I.37, Bento Prado de Almeida Ferraz traz outras que empregam a estrofe alcaica e, em todas aquelas que analisei (I.16, I.17, I.31, I.34, I.35, III.6), verifiquei que prefere traduzir todos os quatro versos da estrofe por decassílabos (HORÁCIO, 2003). Heitor Martins, ao traduzir a ode II.14, usa predominantemente o padrão de três decassílabos, seguidos de um hexassílabo (HORÁCIO, 1970). Elpino Duriense, nas odes II.7 e III.1, também faz essa opção (HORÁCIO, 1941). José Augusto Cabral de Mello, na ode II.13, utiliza, por sua vez, um decassílabo, um hexassílabo, dois decassílabos e mais um hexassílabo e, na ode III.4, três decassílabos seguidos de dois hexassílabos (HORÁCIO, 1853).

A partir dessa breve observação, o que pude constatar foi que as traduções já existentes da estrofe alcaica ou não davam conta da variação de metros (três no total), variação que acredito ser uma característica fundamental dessa forma poética, ou, quando o faziam, aumentavam o número de versos em relação ao poema latino, prática que venho tentando ao máximo evitar em minhas traduções por acreditar que essa inclusão de novos versos seja algo que, para além de descaracterizar o poema em sua forma, também age em um sentido, a meu ver, contrário à economia e síntese características da língua latina.

Assim, por não julgar satisfatório lançar mão de algo préexistente, me vi diante da necessidade de criar uma nova proposta de tradução da estrofe alcaica que, a um só tempo, tentasse dar conta do movimento de variação métrica e tivesse o mesmo número de versos do idioma de partida. $\mathrm{O}$ primeiro passo foi definir quais versos adotar para a manutenção, ou para a compensação, da polimetria latina. Optei por empregar, para os dois primeiros versos, o decassílabo, por ser o verso mais comum na versificação em língua portuguesa. Como a estrofe alcaica faz um movimento de retrocesso no terceiro verso, empregando um verso cuja extensão é consideravelmente inferior aos dois primeiros, lancei mão de um verso mais curto que o decassílabo, mas que ainda permitisse a utilização posterior de um verso intermediário, pois a estrofe faz ainda um movimento de expansão no quarto verso. Usei, então, para o terceiro verso a redondilha maior, ou verso heptassílabo, também escolhido em razão de seu amplo emprego na poesia de língua portuguesa. Desse 
modo, restaram como possibilidades para o quarto verso o octossílabo e o eneassílabo, dentre os quais fiz opção pelo último, também por julgá-lo mais corrente em nosso meio poético. Resumindo, emprego em minha versão da estrofe alcaica, dois decassílabos, uma redondilha maior e um eneassílabo. Além disso, na versão que proponho para a estrofe, também busco aplicar, sempre que possível, um ritmo bem marcado, lançando mão dos esquemas rítmicos mais frequentemente empregados em cada um dos metros escolhidos, tentando tirar o máximo proveito possível da musicalidade do verso em língua portuguesa.

\section{Tradução}

A seguir, apresento a tradução, precedida pelo texto latino, da ode I.37, de Horácio.

Nunc est bibendum, nunc pede libero

pulsanda tellus, nunc Saliaribus

ornare puluinar deorum

tempus erat dapibus, sodales.

Antehac nefas depromere Caecubum

05

cellis auitis, dum Capitolio

regina dementis ruinas

funus et imperio parabat

contaminato cum grege turpium

morbo uirorum, quidlibet impotens

sperare fortunaque dulci

ebria. Sed minuit furorem

uix una sospes nauis ab ignibus, mentemque lymphatam Mareotico

redegit in ueros timores

Caesar, ab Italia uolantem

remis adurgens, accipiter uelut

mollis columbas aut leporem citus

ueuator in campis niualis

Haemoniae, daret ut catenis 
150 Nuntius Antiquus, Belo Horizonte, v. 11, n. 2, p. 143-152, 2015

fatale monstrum. Quae generosius

perire quaerens nec muliebriter

expauit ensem nec latentis

classe cita reparauit oras,

ausa et iacentem uisere regiam

uoltu sereno, fortis et asperas

tractare serpentes, ut atrum

corpore conbiberet uenenum,

deliberata morte ferocior:

saeuis Liburnis scilicet inuidens

priuata deduci superbo, non humilis mulier, triumpho. ${ }^{9}$

Agora é beber, agora, os pés livres,

é a terra pulsar, agora era tempo

de ornar os coxins dos deuses

com os festins sálios, ${ }^{10}$ camaradas.

Ate hoje era ímpio tirar o Cécubo ${ }^{11}$

05

da adega ancestral, enquanto a rainha

tramava insanas ruínas

ao Capitólio ${ }^{12}$ e a morte ao império

${ }^{9}$ Texto latino proveniente de HORACE. Odes et épodes: tome I. Texte établi et trad. par F. Villeneuve. Paris: Les Belles Lettres, 1927, p. 50-51.

${ }^{10}$ Relativo a Marte ou aos seus sacerdotes, entre os romanos. Os festins sálios são, portanto, as oferendas que são feitas ao deus da guerra.

${ }^{11} \mathrm{O}$ Cécubo foi um vinho de grande renome durante a Antiguidade romana. Proveniente de um pequeno território, o ager Caecubus, na costa do Lácio, essa bebida é frequentemente citada como tendo sido o melhor de todos os vinhos: mais suave que o Falerno, mais encorpado que o Albano, era forte e inebriante, um vinho branco que se tornava cor de fogo à medida que envelhecia.

${ }^{12}$ O Capitólio, ou Monte Capitolino, é uma das sete colinas de Roma, em que, na Antiguidade, havia inúmeros templos, sendo o mais importante deles o Templo de Iupiter Optimus Maximus Capitolinus. Construído em 509 a.C., era quase tão grande quanto o Parthenon. O monte e o templo de Júpiter tornaram-se os símbolos de Roma e de seu poder. 
com um bando de homens torpes por vício

corrompido, orgulhosa a esperar seja

o que fosse e ébria da doce

fortuna. Mas abrandou sua fúria

só um navio a custo salvo das chamas,

César reduziu sua mente em delírios

mareóticos ${ }^{13}$ a temores

reais e, desde a Itália correndo,

perseguindo-a a remos, tal qual falcão

as frágeis pombas ou ágil caçador

a lebre nos campos gélidos

da Hemônia, ${ }^{14}$ para pôr em correntes

o monstro fatal. Ela, a morte mais

nobre almejando, não temeu a espada

como as mulheres, nem com

frota veloz buscou praia oculta,

ousou contemplar, com rosto sereno,

seu palácio extinto e, audaz, tocar ásperas

serpentes para que o negro

veneno se entranhasse em seu corpo,

mais feroz na morte deliberada:

nega que a conduzam cruéis liburnas, ${ }^{15}$

como simplória, em soberbo

triunfo, mulher em nada humilde.

${ }^{13}$ Relativo a Mareota, antiga cidade do Baixo Egito, notável pelos vinhos produzidos nas suas cercanias.

${ }^{14}$ Hemônia é o antigo nome da Tessália, região da Grécia.

${ }^{15}$ As liburnas eram embarcações mercantes romanas da Antiguidade, usadas normalmente para o transporte de trigo. 
152 Nuntius Antiquus, Belo Horizonte, v. 11, n. 2, p. 143-152, 2015

\section{Referências}

ANCONA, R. A concise guide to teaching Latin literature. Norman: Oklahoma University Press, 2007.

ANCONA, R. Female Figures in Horace's "Odes". In: DAVIS, G. (org.). A companion to Horace. Chichester/Oxford/Malden: Wiley-Blackwell, 2010, p. 174-192.

CAMPOS, G. Pequeno dicionário de arte poética. 4.ed. Rio de Janeiro: Ediouro, s.d.

DAVIS, G. Polyhymnia: the rhetoric of horatian lyric discourse. Berkeley/Los Angeles/ Oxford: University of California Press, 1991.

HORACE. Odes et epodes: tome I. Texte établi et trad. par F. Villeneuve. Paris: Les Belles Lettres, 1927.

HORÁCIO. Obras completas de Horácio. Trad. Elpino Duriense, José Agostinho de Macedo, Antônio Luiz de Seabra e Francisco Antônio Picot. São Paulo: Edições Cultura, 1941.

HORÁCIO. Odes de Q. Horacio Flacco traduzidas em verso na lingua portugueza, por José Augusto Cabral de Mello. Angra do Heroísmo: Typ. do Angrense, do Visconde de Bruges, 1853.

HORÁCIO. Odes e Epodos. Trad. Bento Prado de Almeida Ferraz. São Paulo: Martins Fontes, 2003.

HORÁCIO. Três odes de Horácio (trad. Heitor Martins). Minas Gerais: suplemento literário, Belo Horizonte, p. 03, 19 dez. 1970.

LOWRIE, M. Horace's Narrative Odes. Oxford: Clarendon Press, 1997. 